\title{
BMJ Open Disparities in selective referral for cancer surgeries: implications for the current healthcare delivery system
}

\author{
Maxine Sun, ${ }^{1}$ Pierre I Karakiewicz, ${ }^{1}$ Jesse D Sammon, ${ }^{2}$ Shyam Sukumar, ${ }^{2}$ \\ Mai-Kim Gervais, ${ }^{3}$ Paul L Nguyen, ${ }^{4}$ Toni K Choueiri, ${ }^{5}$ Mani Menon, ${ }^{2}$ \\ Quoc-Dien Trinh ${ }^{6}$
}

To cite: Sun M, Karakiewicz PI, Sammon JD, et al. Disparities in selective referral for cancer surgeries: implications for the current healthcare delivery system. BMJ Open 2014;4:e003921. doi:10.1136/bmjopen-2013003921

- Prepublication history for this paper is available online. To view these files please visit the journal online (http://dx.doi.org/10.1136/ bmjopen-2013-003921).

MS and PIK contributed equally.

Received 1 September 2013 Revised 16 January 2014 Accepted 21 January 2014

CrossMark

For numbered affiliations see end of article.

Correspondence to Dr Maxine Sun; mcw.sun@umontreal.ca

\section{ABSTRACT}

Objectives: Among considerable efforts to improve quality of surgical care, expedited measures such as a selective referral to high-volume institutions have been advocated. Our objective was to examine whether racial, insurance and/or socioeconomic disparities exist in the use of high-volume hospitals for complex surgical oncological procedures within the USA. Design, setting and participants: Patients undergoing colectomy, cystectomy, oesophagectomy, gastrectomy, hysterectomy, lung resection, pancreatectomy or prostatectomy were identified retrospectively, using the Nationwide Inpatient Sample, between years 1999 and 2009. This resulted in a weighted estimate of 2508916 patients.

Primary outcome measures: Distribution of patients according to race, insurance and income characteristics was examined according to low-volume and high-volume hospitals (highest $20 \%$ of patients according to the procedure-specific mean annual volume). Generalised linear regression models for prediction of access to high-volume hospitals were performed.

Results: Insurance providers and county income levels varied differently according to patients' race. Most Caucasians resided in wealthier counties, regardless of insurance types (private/Medicare), while most African Americans resided in less wealthy counties ( $\leq \$ 24999)$, despite being privately insured. In general, Caucasians, privately insured, and those residing in wealthier counties ( $\geq \$ 45000$ ) were more likely to receive surgery at high-volume hospitals, even after adjustment for all other patient-specific characteristics. Depending on the procedure, some disparities were more prominent, but the overall trend suggests a collinear effect for race, insurance type and county income levels.

Conclusions: Prevailing disparities exist according to several patient and sociodemographic characteristics for utilisation of high-volume hospitals. Efforts should be made to directly reduce such disparities and ensure equal healthcare delivery.

\section{INTRODUCTION}

There is empirical evidence suggesting that hospital volume represents an established

\section{Strengths and limitations of this study}

- The study examined eight major surgical oncological procedures.

- The study relied on a large population-based cohort representative of the USA.

- No additional information on disease characteristics was available, possibly confounding the observed effect.

proxy for better quality of care after complex surgical oncological procedures. ${ }^{1-7}$ In consequence, amid many efforts to improve quality of surgical care, expedited measures such as a selective referral to high-volume institutions have been advocated. ${ }^{8-10}$

In this instance, there has been a remarkable progress in the reduction of adverse outcomes following a major surgical oncological procedure, which includes decreasing cancer death rates in the USA over the past two decades. $^{11}$ Nonetheless, improvements are not consistent across all population strata. ${ }^{12} 13$ For example, reduction in cancer deaths in persons with low socioeconomic status and in African Americans remains slow. Such lack of improvement in selected segments of the US population may suggest underlying disparities, ${ }^{12}{ }^{14}$ among them access to care. ${ }^{15}$ Consequently, eliminating such disparities across various levels of sociodemographic factors represents an overreaching objective of several initiatives that have been implemented by several organisations-among them, the American Cancer Society ${ }^{16}$ and the US Department of Health and Human Services Health People initiative. $^{17}$

In the context of such extensive collaborative efforts, further data are needed to better describe the disparities in the regionalisation process. The current study seeks to assess specific sociodemographic characteristics 
and utilisation of high-volume hospitals across major surgical oncological procedures performed in the USA during the last decade. Our hypothesis states that some sociodemographic characteristics are consistently associated with inferior access to high-volume hospital care.

\section{MATERIALS AND METHODS \\ Data source}

Relying on the Nationwide Inpatient Sample (NIS), hospital discharges in the USA between 1 January 1999 and 30 December 2009 were abstracted. The NIS is a set of longitudinal hospital inpatient databases included in the Healthcare Cost and Utilization Project family, created by the Agency for Healthcare Research and Quality through a Federal-state partnership. ${ }^{18}$ The database includes discharge abstracts from eight million hospital stays and incorporates patient and hospital information, including patients covered by Medicare, Medicaid, private insurance and other insurance types.

Each discharge includes up to 15 inpatient diagnoses and procedures per hospitalisation. All procedures and diagnoses are coded using the International Classification of Disease, $9^{\text {th }}$ revision, Clinical Modification (ICD-9-CM). Included patient and sociodemographic characteristics are patient sex, race, age, expected source of payment, ZIP code of residence, outcomes (intraoperative and postoperative complications during hospitalisation, in-hospital mortality), as well as hospital information (unique hospital identifier, hospital location). Patients' socioeconomic status is also available using a proxy income, defined by county-specific ZIP code according to the US census.

\section{Study cohort}

A total of eight major surgical oncological procedures were selected for evaluation of the volume-disparity relationship: colectomy, cystectomy, oesophagectomy, gastrectomy, hysterectomy, pneumonectomy, pancreatectomy and prostatectomy. Analyses were restricted to cancer diagnoses only. Relying on specific ICD-9-CM procedure codes (available on request), each surgical procedure was assessed independently.

\section{Primary outcome}

The primary dependent variable of interest was hospital volume, classified as high-volume, medium-volume and low-volume hospitals. Hospital volume was defined according to previously described methodology. ${ }^{19}$ Specifically, hospital volume for each given surgical oncological procedure was determined according to its mean annual procedural volume, namely the number of procedures performed overall divided by the number of years the hospital performed the operation, for the entire study period (1999-2009). Such measure compensates for the fluctuation of varying hospital volume overtime, and represents an aggregation of overall procedure-specific experience for the entire study span of analysis. Subsequently, hospital volume was categorised into three groups using patient quintiles, where high-volume hospitals were formed by patients within the first $20 \%$ of patients according to mean annual volume, medium-volume hospitals were formed by patients within the middle $60 \%$, and low-volume hospitals represented the lowest $20 \%$ of patients. It is noteworthy that hospital volume was also examined as a continuous variable for methodological stringency. However, categorisation of hospital volume into groups was deemed as more optimal for the purpose of clinical interpretation.

\section{Patient and hospital characteristics}

Available independent variables for analyses included patient age at hospitalisation, race, sex, insurance status, baseline comorbidities, patient ZIP code income, as well as hospital location. Information on race was categorised as Caucasian, African American, Hispanic, other (Asian or Pacific Islander, Native American) or unknown. Given that approximately $25 \%$ of patients were of unknown race, we chose not to exclude these patients from the entire cohort so as not to induce any bias. That said, stratified bivariate analyses omitted its consideration as it would be difficult to interpret and properly comment on patients with missing race information. Insurance status was classified based on the expected primary payer, and included Medicare, Medicaid, private insurance (Blue Cross, commercial carriers, private HMOs and PPOs) and other insurance types including those who were uninsured. Patient age was considered as a continuous variable. Baseline comorbidities were determined using a Charlson comorbidity index-derived score, ${ }^{20}$ adapted by Deyo et $a l,{ }^{21}$ and assessed as a continuous variable.

Income at the patient level was not available within the NIS. In consequence, we relied on the median household income of the patient's ZIP code of residence, which was derived from the US census. Four categories were available within the database ${ }^{1}:<\$ 25000,{ }^{2}$ $\$ 25$ 000-\$34 999,,$^{3} \$ 35000-\$ 44999$ and $^{4} \geq \$ 45000$.

\section{Statistical analyses}

In order to make national estimates of the number of discharges more accurate, the crude distribution was weighted according to the provided NIS population weights. All subsequent analyses were performed on the weighted population.

Baseline descriptives were generated for sex, race, insurance status and income stratified according to hospital volume categories. Univariable analysis was computed whenever appropriate using $\chi^{2}$ and independent sample $t$ tests for categorical and continuous variables, respectively. Generalised linear regression models were used to examine the impact of the primary predictors (race, insurance status, income) on access to highvolume hospital. Adjustment was made for patient age and baseline comorbidities. Year of surgery was 
modelled as a random effect. In contrast, adjustment for clustering of hospitals was not made given that hospitals represented the dependent variable of interest. The odds of receiving care at high-volume hospitals were calculated. All tests were two-sided with statistical significance set at $\mathrm{p}<0.05$. Analyses were conducted using the $\mathrm{R}$ statistical package (the $\mathrm{R}$ foundation for Statistical Computing, V.2.15.0).

\section{RESULTS}

\section{Baseline descriptives}

A weighted estimate of 2508916 patients underwent one of the eight examined procedures. Baseline sociodemographic characteristics in the entire cohort are described in table 1 . Mean age was 66 years (median 66). Sociodemographic characteristics differed according to procedure type. For example, patients in the prostatectomy group were youngest (median 62) and those in the colectomy group were oldest (median 72). Across nearly all surgeries, the majority of patients were Caucasian and ranged from $48 \%$ to $67 \%$ for gastrectomy and cystectomy, respectively. With respect to insurance status, privately insured patients ranged from $29 \%$ to $64 \%$ for colectomy and prostatectomy, respectively. Patients with Medicare insurance ranged from $30 \%$ to $64 \%$ for prostatectomy and colectomy, respectively. The proportion of patients with the highest ZIP code income $(\geq \$ 45000)$ ranged between $30 \%$ and $38 \%$ for colectomy and prostatectomy, respectively.

Subsequently, patients' race, insurance status and income levels were assessed in the entire cohort (table 2). Among Caucasians, most patients had high income $(\geq \$ 45000)$, regardless of being privately insured $(42 \%)$ or having Medicare coverage (32\%). Similar trends were recorded among Hispanics and persons of other races. In contrast, among African Americans, despite being privately insured, the majority of patients had low income ( $\leq \$ 24$ 000: 27\%). These associations were subsequently confirmed within each procedure (data not shown).

\section{Bivariate associations for hospital volume}

Table 3 shows overall descriptions of race, insurance types and income levels stratified according to lowhospital and high-hospital volume. For all procedure types, patients' sociodemographic factors differed significantly according to hospital volume (all $\mathrm{p} \leq 0.01$ ), where Caucasian, private insurance and high-income patients were more likely to be treated at high volume, while African American/Hispanic, Medicare/Medicaid, and low-income patients were more likely to be treated at low-volume hospitals. The lowest and highest proportions of individuals of Caucasian race who were treated at high-volume hospitals were recorded for gastrectomy $(50 \%)$ and oesophagectomy/lung resections (both $73 \%)$, respectively. With respect to patients with private insurance, the lowest and highest proportions of individuals treated at high-volume hospitals were observed for colectomy (34\%) and prostatectomy (71\%), respectively. The lowest and highest proportions of patients with a median ZIP code income of $\geq \$ 45000$ treated at highvolume hospitals were recorded for cystectomy (28\%) and prostatectomy (46\%), respectively.

\section{Insurance and hospital volume according to race}

Subsequently, a more detailed stratification was performed. Specifically, we examined the relationship between hospital volume and insurance status for each race group (table 4). Most importantly, regardless of race, those privately insured were more frequently treated at high-volume than low-volume hospitals in the settings of colectomy, cystectomy, lung resections, pancreatectomy and prostatectomy. In contrast, Medicare patients were more frequently treated at low-volume hospitals. However, this observation did not apply to oesophagectomies performed on African Americans and Hispanics. In these groups, Medicare beneficiaries were more frequently treated at high-volume than low-volume hospitals (African Americans: 49\% vs 37\%, Hispanics: $55 \%$ vs $41 \%$ ), while privately insured patients were more frequently treated at low-volume than high-volume hospitals (African Americans: 32\% vs 26\%, Hispanics: 36\% vs $24 \%$, all $\mathrm{p}<0.001)$. For hysterectomy, African Americans with Medicare coverage were more frequently treated at high-volume than low-volume hospitals $(48 \%$ vs $44 \%, \mathrm{p}<0.001)$.

\section{Income and hospital volume according to race}

A second more detailed stratification was performed in order to examine the relationship between hospital volume and ZIP code income for each race group (table $5)$. Most importantly, regardless of race, patients with the highest income $(\geq \$ 45000)$ were more frequently treated at high-volume hospitals for colectomy, gastrectomy, hysterectomy and prostatectomy. This relationship did not apply to cystectomy, oesophagectomy and pancreatectomy. Specifically, the proportions of Caucasians with high income treated at low-volume and highvolume hospitals were similar $(33 \%$ vs $30 \%)$. Moreover, most oesophagectomies were performed on African Americans who had low income $(<\$ 25000)$ and were treated in high-volume hospitals (87\%). Among African Americans treated with pancreatectomy, the majority had low income $(<\$ 25000)$.

\section{Generalised linear regression models}

Figure 1A illustrates the multivariable effect of race for prediction of high-volume hospital utilisation. For seven of the eight procedures (cystectomy, oesophagectomy, gastrectomy, hysterectomy, lung resection, pancreatectomy and prostatectomy), African Americans and/or Hispanics predisposed to lower rates of treatment at high-volume hospitals relative to their Caucasian race counterparts (OR 0.21-0.93). Figure 1B illustrates the multivariable effect of insurance status. For six of the eight procedures (colectomy, cystectomy, gastrectomy, 
Table 1 Baseline descriptive characteristics according to eight major surgical oncological procedures*

\begin{tabular}{|c|c|c|c|c|c|c|c|c|c|}
\hline Variables & Total & Colectomy & Cystectomy & Oesophagectomy & Gastrectomy & Hysterectomy & Lung & Pancreatectomy & RP \\
\hline Number of patients (\%) & 100 & 37 & 3.2 & 0.7 & 3.3 & 9.8 & 14.6 & 2.3 & 29.1 \\
\hline \multicolumn{10}{|l|}{ Hospital volume } \\
\hline Mean (median) & - & $46(39)$ & $19(8)$ & $7(4)$ & $9(5)$ & $32(23)$ & 42 (29) & $19(10)$ & $117(64)$ \\
\hline IQR & & $22-62$ & $4-22$ & $2-11$ & $3-10$ & $10-48$ & $15-51$ & $4-23$ & $28-137$ \\
\hline \multicolumn{10}{|l|}{ Age (years) } \\
\hline Mean (median) & $66(66)$ & $70(72)$ & $68(70)$ & $64(64)$ & $67(69)$ & $63(62)$ & $67(68)$ & $65(66)$ & $62(62)$ \\
\hline IQR & $58-74$ & $62-80$ & $62-76$ & $56-71$ & $58-77$ & $54-72$ & $60-74$ & $57-74$ & $56-67$ \\
\hline Female (\%) & 40 & 53 & 18 & 20 & 39 & 100 & 49 & 50 & 0 \\
\hline \multicolumn{10}{|l|}{ Race (\%) } \\
\hline Caucasian & 61 & 60 & 67 & 64 & 48 & 61 & 66 & 61 & 60 \\
\hline African American & 7 & 8 & 4 & 5 & 10 & 5 & 5 & 7 & 8 \\
\hline Hispanic & 4 & 4 & 3 & 3 & 10 & 4 & 2 & 6 & 4 \\
\hline Others & 4 & 4 & 3 & 3 & 10 & 4 & 3 & 5 & 3 \\
\hline Unknown & 25 & 25 & 25 & 26 & 21 & 26 & 24 & 23 & 25 \\
\hline \multicolumn{10}{|l|}{ Insurance status (\%) } \\
\hline Private & 42 & 29 & 31 & 46 & 32 & 49 & 34 & 40 & 64 \\
\hline Medicaid & 3 & 3 & 4 & 6 & 7 & 4 & 4 & 5 & 2 \\
\hline Medicare & 51 & 64 & 62 & 44 & 56 & 42 & 59 & 50 & 30 \\
\hline Others & 4 & 4 & 4 & 4 & 5 & 5 & 4 & 5 & 4 \\
\hline \multicolumn{10}{|l|}{ Median income (\%) } \\
\hline$<\$ 25000$ & 15 & 17 & 15 & 16 & 18 & 12 & 16 & 16 & 12 \\
\hline$\$ 25000-\$ 34999$ & 24 & 26 & 25 & 24 & 24 & 22 & 24 & 23 & 21 \\
\hline$\$ 35000-\$ 44999$ & 26 & 26 & 27 & 26 & 24 & 26 & 26 & 25 & 26 \\
\hline$\geq \$ 45000$ & 34 & 30 & 32 & 32 & 32 & 37 & 32 & 34 & 38 \\
\hline Unknown & 2 & 2 & 2 & 2 & 2 & 2 & 2 & 3 & 3 \\
\hline
\end{tabular}

${ }^{*}$ Rates are weighted according to the NIS-assigned discharge weights.

NIS, Nationwide Inpatient Sample; RP, radical prostatectomy. 
Table 2 Bivariate associations between insurance types and income, stratified according to race*

\begin{tabular}{|c|c|c|c|c|c|}
\hline \multirow[b]{2}{*}{ Race } & \multirow[b]{2}{*}{ Insurance status } & \multicolumn{4}{|c|}{ Income groups } \\
\hline & & $<\$ 25000$ & $\$ 25000-\$ 34999$ & $\$ 35000-\$ 44999$ & $\geq \$ 45000$ \\
\hline \multirow[t]{4}{*}{ Caucasian } & Private & 9.5 & 20.5 & 26.2 & 41.7 \\
\hline & Medicaid & 23.9 & 30.3 & 24.1 & 19.1 \\
\hline & Medicare & 13.4 & 25.6 & 26.8 & 32.2 \\
\hline & Other & 16.5 & 29.0 & 25.8 & 24.5 \\
\hline \multirow[t]{4}{*}{ African American } & Private & 27.2 & 23.9 & 23.0 & 23.6 \\
\hline & Medicaid & 46.9 & 23.6 & 15.2 & 10.7 \\
\hline & Medicare & 38.5 & 26.2 & 18.7 & 14.6 \\
\hline & Other & 36.4 & 25.6 & 18.6 & 14.4 \\
\hline \multirow[t]{4}{*}{ Hispanic } & Private & 20.4 & 21.5 & 25.0 & 29.2 \\
\hline & Medicaid & 38.5 & 25.0 & 22.3 & 12.1 \\
\hline & Medicare & 28.4 & 23.7 & 23.1 & 22.0 \\
\hline & Other & 30.6 & 21.0 & 22.0 & 18.5 \\
\hline \multirow[t]{4}{*}{ Others } & Private & 8.6 & 15.5 & 23.0 & 50.9 \\
\hline & Medicaid & 16.9 & 20.5 & 23.1 & 32.9 \\
\hline & Medicare & 14.4 & 20.4 & 24.8 & 38.5 \\
\hline & Other & 15.2 & 19.8 & 23.1 & 31.3 \\
\hline
\end{tabular}

hysterectomy, lung resection and prostatectomy), Medicare, Medicaid and/or other insurance types were less likely to be treated at high-volume hospitals compared to privately insured individuals (OR 0.52-0.87). Finally, in figure 1C, the multivariable effect of ZIP code income is shown. For six of the eight procedures (colectomy, oesophagectomy, gastrectomy, hysterectomy, lung resection and prostatectomy), high income ( $\geq \$ 45000)$ was associated with a higher rate of high-volume hospitals utilisation relative to their lowest income counterparts (OR 1.32-1.92).

\section{DISCUSSION}

The importance of the volume-outcome relationship or, more precisely, whether higher volume institutions are independently associated with worse outcomes has been intricately debated in the past two decades. ${ }^{3-5} 22-27$ At present, most would agree that procedural volume at least represents a proxy for better quality of care following a major procedure. ${ }^{1-7} 9$ This has led to payer-led initiatives, such as the Leapfrog Group for Patient Safety, ${ }^{8} 10$ advocating the utilisation of high-volume institutions on a national level. Following the implementation of such programmes, some studies have noted a discrepancy in the utilisation of high-volume hospitals across various sociodemographic populations. ${ }^{15} 19$ For example, previous studies showed that persons of African American race were less likely to receive care at a high-volume hospital than their Caucasian race counterparts. ${ }^{15} 19$ Disparities have also been observed according to a patient's insurance status, where most studies alluded to difficulties in accessing high-volume hospitals among patients with Medicaid/Medicare insurance types. ${ }^{15}$ In addition, disparities have consistently been reported for persons with poverty. ${ }^{15} 2829$

Theoretically, equal access to care for all segments of the population with regard to cancer prevention, early detection and treatment can significantly reduce disparities in cancer care, and ultimately reduce the incidence of adverse outcomes during hospitalisation. In order to achieve this target, more research is needed to better specify public health interventions. As such, the purpose of the current study was to examine whether disparities with respect to race, insurance and income levels exist for receipt of care at high-volume institutions across eight major oncological procedures.

Our hypothesis stated that disparities pertaining to race, insurance status and income levels may exist with respect to utilisation of high-volume hospitals. Specifically, we postulated that African Americans/ Hispanics, non-privately insured individuals and lowincome level patients are less likely to be treated at highvolume hospitals. Our bivariate analyses confirmed this hypothesis. Moreover, our multivariable analysis further corroborated this suspicion. Indeed, African Americans/ Hispanics and non-privately insured patients had lower rates of high-volume hospital utilisation in $7 / 8$ and $6 / 8$ procedures, respectively. In contrast, patients residing in high-income neighbourhoods were more likely to be treated at high-volume hospitals in $6 / 8$ procedures.

Taken together, our data convincingly demonstrate that African Americans/Hispanics, non-privately insured and low-income individuals were significantly more likely to be treated at low-volume hospitals. This occurred in the majority of the examined scenarios. This implies that racial, insurance and income-related disparities affect access to treatment at high-volume hospitals. Limited access to treatment at high-volume hospitals is 
Table 3 Weighted proportions (\%) of race, insurance status and median income stratified according to procedure-specific low-hospital and high-hospital volume*

\begin{tabular}{|c|c|c|c|}
\hline & $\begin{array}{l}\text { Low } \\
\text { volume }\end{array}$ & $\begin{array}{l}\text { High } \\
\text { volume }\end{array}$ & p Value \\
\hline \multicolumn{4}{|l|}{ Colectomy } \\
\hline Race & & & $<0.001$ \\
\hline Caucasian & 58.8 & 62.7 & \\
\hline African American & 6.7 & 7.8 & \\
\hline Hispanic & 5.0 & 4.2 & \\
\hline Others & 3.6 & 4.0 & \\
\hline Insurance status & & & $<0.001$ \\
\hline Private & 23.6 & 33.5 & \\
\hline Medicaid & 4.4 & 2.6 & \\
\hline Medicare & 66.4 & 61.4 & \\
\hline Others & 5.6 & 2.5 & \\
\hline Median income & & & $<0.001$ \\
\hline$<\$ 25000$ & 22.7 & 13.4 & \\
\hline$\$ 25000-\$ 34999$ & 34.3 & 19.5 & \\
\hline$\$ 35000-\$ 44999$ & 24.4 & 24.5 & \\
\hline$\geq \$ 45000$ & 15.9 & 40.8 & \\
\hline \multicolumn{4}{|l|}{ Cystectomy } \\
\hline Race & & & $<0.001$ \\
\hline Caucasian & 64.5 & 69.6 & \\
\hline African American & 3.9 & 2.6 & \\
\hline Hispanic & 3.4 & 3.7 & \\
\hline Others & 2.9 & 3.8 & \\
\hline Insurance status & & & $<0.001$ \\
\hline Private & 26.9 & 35.6 & \\
\hline Medicaid & 4.3 & 3.3 & \\
\hline Medicare & 64.8 & 56.5 & \\
\hline Others & 4.0 & 4.6 & \\
\hline Median income & & & $<0.001$ \\
\hline$<\$ 25000$ & 13.6 & 17.7 & \\
\hline$\$ 25000-\$ 34999$ & 26.5 & 27.9 & \\
\hline$\$ 35000-\$ 44999$ & 27.8 & 24.3 & \\
\hline$\geq \$ 45000$ & 29.8 & 28.0 & \\
\hline \multicolumn{4}{|l|}{ Oesophagectomy } \\
\hline Race & & & $<0.001$ \\
\hline Caucasian & 56.5 & 72.2 & \\
\hline African American & 8.4 & 1.1 & \\
\hline Hispanic & 3.8 & 4.5 & \\
\hline Others & 4.2 & 3.0 & \\
\hline Insurance status & & & 0.010 \\
\hline Private & 42.8 & 47.9 & \\
\hline Medicaid & 8.3 & 4.2 & \\
\hline Medicare & 43.5 & 44.7 & \\
\hline Others & 5.5 & 3.2 & \\
\hline Median income & & & 0.032 \\
\hline$<\$ 25000$ & 18.3 & 14.2 & \\
\hline$\$ 25000-\$ 34999$ & 25.3 & 23.2 & \\
\hline$\$ 35000-\$ 44999$ & 26.6 & 27.0 & \\
\hline$\geq \$ 45000$ & 28.5 & 31.9 & \\
\hline \multicolumn{4}{|l|}{ Gastrectomy } \\
\hline Race & & & $<0.001$ \\
\hline Caucasian & 46.8 & 50.2 & \\
\hline African American & 11.7 & 9.3 & \\
\hline Hispanic & 9.5 & 9.5 & \\
\hline Others & 5.8 & 15.3 & \\
\hline
\end{tabular}

Continued
Table 3 Continued

\begin{tabular}{|c|c|c|c|}
\hline & $\begin{array}{l}\text { Low } \\
\text { volume }\end{array}$ & $\begin{array}{l}\text { High } \\
\text { volume }\end{array}$ & p Value \\
\hline Insurance status & & & $<0.001$ \\
\hline Private & 25.3 & 38.8 & \\
\hline Medicaid & 6.4 & 8.1 & \\
\hline Medicare & 62.4 & 47.6 & \\
\hline Others & 5.8 & 5.4 & \\
\hline Median income & & & $<0.001$ \\
\hline$<\$ 25000$ & 20.3 & 18.7 & \\
\hline$\$ 25000-\$ 34999$ & 30.7 & 19.0 & \\
\hline$\$ 35000-\$ 44999$ & 25.4 & 19.6 & \\
\hline$\geq \$ 45000$ & 21.4 & 40.5 & \\
\hline \multicolumn{4}{|l|}{ Hysterectomy } \\
\hline Race & & & $<0.001$ \\
\hline Caucasian & 59.6 & 63.7 & \\
\hline African American & 4.4 & 4.4 & \\
\hline Hispanic & 4.8 & 2.2 & \\
\hline Others & 3.7 & 3.4 & \\
\hline Insurance status & & & $<0.001$ \\
\hline Private & 44.2 & 54.2 & \\
\hline Medicaid & 5.1 & 3.8 & \\
\hline Medicare & 44.4 & 38.6 & \\
\hline Others & 6.3 & 3.4 & \\
\hline Median income & & & $<0.001$ \\
\hline$<\$ 25000$ & 15.0 & 10.9 & \\
\hline$\$ 25000-\$ 34999$ & 30.5 & 18.3 & \\
\hline$\$ 35000-\$ 44999$ & 26.8 & 25.7 & \\
\hline$\geq \$ 45000$ & 25.4 & 43.5 & \\
\hline \multicolumn{4}{|l|}{ Lung resection } \\
\hline Race & & & $<0.001$ \\
\hline Caucasian & 60.9 & 72.7 & \\
\hline African American & 6.6 & 4.2 & \\
\hline Hispanic & 3.8 & 1.6 & \\
\hline Others & 3.7 & 2.7 & \\
\hline Insurance status & & & $<0.001$ \\
\hline Private & 30.7 & 38.0 & \\
\hline Medicaid & 5.7 & 3.6 & \\
\hline Medicare & 58.9 & 55.5 & \\
\hline Others & 4.7 & 2.9 & \\
\hline Median income & & & $<0.001$ \\
\hline$<\$ 25000$ & 16.6 & 15.6 & \\
\hline$\$ 25000-\$ 34999$ & 27.9 & 21.1 & \\
\hline$\$ 35000-\$ 44999$ & 25.7 & 23.0 & \\
\hline$\geq \$ 45000$ & 27.7 & 38.0 & \\
\hline \multicolumn{4}{|l|}{ Pancreatectomy } \\
\hline Race & & & $<0.001$ \\
\hline Caucasian & 56.0 & 65.6 & \\
\hline African American & 8.4 & 4.1 & \\
\hline Hispanic & 6.1 & 5.4 & \\
\hline Others & 4.5 & 2.7 & \\
\hline Insurance status & & & $<0.001$ \\
\hline Private & 36.2 & 42.4 & \\
\hline Medicaid & 5.8 & 4.2 & \\
\hline Medicare & 52.9 & 49.1 & \\
\hline Others & 5.1 & 4.3 & \\
\hline Median income & & & $<0.001$ \\
\hline$<\$ 25000$ & 15.3 & 17.7 & \\
\hline
\end{tabular}


Table 3 Continued

\begin{tabular}{lccc}
\hline & $\begin{array}{l}\text { Low } \\
\text { volume }\end{array}$ & $\begin{array}{l}\text { High } \\
\text { volume }\end{array}$ & p Value \\
\hline \$25 000-\$34999 & 24.9 & 24.0 & \\
\$35 000-\$44999 & 26.8 & 23.1 & \\
$\geq \$ 45000$ & 30.8 & 31.4 & \\
Prostatectomy & & & \\
Race & & & $<0.001$ \\
Caucasian & 56.5 & 62.4 & \\
African American & 9.1 & 7.1 & \\
Hispanic & 5.2 & 3.3 & \\
Others & 3.6 & 3.7 & \\
Insurance status & & & \\
Private & 57.7 & 70.5 & \\
Medicaid & 2.5 & 1.3 & \\
Medicare & 33.9 & 25.2 & \\
Others & 5.9 & 3.0 & \\
Median income & & & \\
<25 000 & 15.7 & 10.8 & \\
\$25 000-\$34 999 & 27.2 & 17.7 & \\
\$35 000-\$44 999 & 26.2 & 22.6 & \\
$\geq \$ 45000$ & 28.1 & 45.8 & \\
*Percentages may not sum to 100 because unknown race and \\
ZIP code median income are not listed. & & \\
\end{tabular}

ultimately linked to limited access to academic centres, hospitals located in the urban setting, hospitals with better bed-size capacity and increased market concentration, since high-volume hospitals are often characterised with such features. ${ }^{23}$ Such patterns of care have been shown to result in suboptimal outcomes according to the practice-makes-perfect hypothesis. Therefore, these access-related disparities should be addressed to ensure optimal outcomes.

It is also noteworthy that the observed disparities often reflected overlapping and embedded effects of the examined sociodemographic characteristics, and varied according to procedures. For example, patients with private insurance often lived in ZIP code areas with higher income. However, this was only true for Caucasians. In African Americans, despite being privately insured, most patients lived in areas with the lowest income $(<\$ 25000)$. Similarly, most Caucasian patients with Medicare insurance had high income, while most African American patients with Medicare insurance had low income. Hence, racial, insurance or income disparities are not separate singular effects, but a weaving of all such denominators, which ultimately come to influence access to care. Indeed, the causes of disparities in cancer care across different sociodemographic groups are complex, and often represent interrelated social, economic, cultural and healthcare system factors. From the perspective of healthcare policies, such a mosaic of interrelations may not be entirely inopportune, since the interception of one disparity will eventually affect other associated disparities. However, it should be noted that specific patterns of high-volume hospital utilisation may apply to different cancer sites.
Table 4 Distribution of patients' insurance status across low-volume and high-volume hospitals according to race groups, stratified according to each procedure

\begin{tabular}{|c|c|c|c|c|}
\hline & \multicolumn{4}{|c|}{ Low volumelhigh volume (\%) } \\
\hline & Caucasian & $\begin{array}{l}\text { African } \\
\text { American }\end{array}$ & Hispanic & Others \\
\hline \multicolumn{5}{|l|}{ Colectomy } \\
\hline Private & $23 \mid 30$ & $25 \mid 40$ & $24 \mid 35$ & $24 \mid 41$ \\
\hline Medicaid & 312 & 1216 & 1218 & 1318 \\
\hline Medicare & 70167 & 53150 & 52152 & $54 \mid 48$ \\
\hline Others & 412 & 1014 & 1315 & 1014 \\
\hline \multicolumn{5}{|l|}{ Cystectomy } \\
\hline Private & $27 \mid 36$ & $24 \mid 37$ & $26 \mid 24$ & 20129 \\
\hline Medicaid & $3 \mid 3$ & $11 \mid 12$ & $13 \mid 14$ & $13 \mid 7$ \\
\hline Medicare & $67 \mid 57$ & 60143 & $49 \mid 45$ & $58 \mid 59$ \\
\hline Others & $4 \mid 4$ & 518 & $11 \mid 16$ & 816 \\
\hline \multicolumn{5}{|c|}{ Oesophagectomy } \\
\hline Private & 45150 & 32126 & $36 \mid 24$ & 42162 \\
\hline Medicaid & 614 & 22126 & 1119 & 310 \\
\hline Medicare & $46 \mid 44$ & 37149 & $41 \mid 55$ & 52125 \\
\hline Others & $4 \mid 3$ & 1010 & $12 \mid 12$ & $3 \mid 13$ \\
\hline \multicolumn{5}{|c|}{ Hysterectomy } \\
\hline Private & $45 \mid 54$ & $34 \mid 41$ & $41 \mid 49$ & 48162 \\
\hline Medicaid & $3 \mid 3$ & $15 \mid 8$ & $17 \mid 16$ & $15 \mid 5$ \\
\hline Medicare & $47 \mid 41$ & $44 \mid 48$ & 31128 & 26128 \\
\hline Others & $6 \mid 3$ & $8 \mid 3$ & $12 \mid 7$ & $11 \mid 5$ \\
\hline \multicolumn{5}{|l|}{ Gastrectomy } \\
\hline Private & $24 \mid 42$ & $24 \mid 33$ & $25 \mid 31$ & $24 \mid 31$ \\
\hline Medicaid & $3 \mid 4$ & $9 \mid 11$ & $17 \mid 17$ & $12 \mid 16$ \\
\hline Medicare & $69 \mid 50$ & 60148 & $47 \mid 42$ & $52 \mid 45$ \\
\hline Others & $4 \mid 3$ & $7 \mid 8$ & $11 \mid 10$ & $13 \mid 7$ \\
\hline \multicolumn{5}{|c|}{ Lung resection } \\
\hline Private & $31 \mid 38$ & 29139 & $23 \mid 42$ & 29138 \\
\hline Medicaid & $4 \mid 3$ & $11 \mid 11$ & $14 \mid 11$ & 1419 \\
\hline Medicare & $61 \mid 57$ & $53 \mid 46$ & $55 \mid 42$ & $50 \mid 48$ \\
\hline Others & $4 \mid 3$ & $7 \mid 4$ & 815 & 815 \\
\hline \multicolumn{5}{|c|}{ Pancreatectomy } \\
\hline Private & $36 \mid 43$ & $35 \mid 40$ & $27 \mid 40$ & $30 \mid 40$ \\
\hline Medicaid & 313 & $12 \mid 12$ & $19 \mid 17$ & $17 \mid 3$ \\
\hline Medicare & $57 \mid 51$ & $48 \mid 40$ & 45133 & $42 \mid 42$ \\
\hline Others & $4 \mid 3$ & 617 & $10 \mid 11$ & $11 \mid 15$ \\
\hline \multicolumn{5}{|c|}{ Prostatectomy } \\
\hline Private & $27 \mid 36$ & $24 \mid 37$ & $26 \mid 24$ & 20129 \\
\hline Medicaid & $3 \mid 3$ & $11 \mid 12$ & $13 \mid 14$ & $13 \mid 7$ \\
\hline Medicare & $67 \mid 57$ & 60143 & $49 \mid 45$ & 58159 \\
\hline Others & $4 \mid 4$ & 518 & $11 \mid 16$ & 816 \\
\hline
\end{tabular}

Therefore, cancer-specific interventions aimed at reducing such disparities may be required.

While the reasons for why disparities occur remain unclear, what is definite is that barriers in accessing higher quality of care have a direct impact on early cancer detection and treatment. Under these circumstances, it has long been stated that "poverty is a carcinogen,"-a cancer-causing agent. ${ }^{31}$ For this reason, effective policies and public health programmes have been implemented to promote overall health awareness among minorities and medically undeserved populations in the USA. ${ }^{32}$ 
Table 5 Distribution of patients' ZIP code income levels across low-volume and high-volume hospitals according to race groups, stratified according to each procedure

\begin{tabular}{|c|c|c|c|c|}
\hline & \multicolumn{4}{|c|}{ Low volumelhigh volume (\%) } \\
\hline & Caucasian & African American & Hispanic & Others \\
\hline \multicolumn{5}{|l|}{ Colectomy } \\
\hline$\$ 25000-\$ 34999$ & 35120 & 29123 & $25 \mid 21$ & $24 \mid 18$ \\
\hline$\$ 35000-\$ 44999$ & $26 \mid 25$ & $15 \mid 18$ & $19 \mid 28$ & 27122 \\
\hline$\geq \$ 45000$ & $18 \mid 42$ & $11 \mid 17$ & $15 \mid 24$ & $26 \mid 47$ \\
\hline$\$ 25000-\$ 34999$ & $27 \mid 27$ & 20118 & $27 \mid 16$ & $16 \mid 20$ \\
\hline$\$ 35000-\$ 44999$ & $26 \mid 25$ & $23 \mid 18$ & $26 \mid 27$ & $28 \mid 26$ \\
\hline$\geq \$ 45000$ & $33 \mid 30$ & $18 \mid 19$ & $18 \mid 17$ & $36 \mid 41$ \\
\hline \multicolumn{5}{|l|}{ Oesophagectomy } \\
\hline$<\$ 25000$ & $14 \mid 13$ & $45 \mid 87$ & $33 \mid 18$ & $14 \mid 16$ \\
\hline$<\$ 25000$ & $12 \mid 8$ & $29 \mid 35$ & $35 \mid 32$ & $9 \mid 9$ \\
\hline$\$ 25000-\$ 34999$ & $31 / 19$ & 29121 & $23 \mid 19$ & $22 \mid 18$ \\
\hline$\$ 35000-\$ 44999$ & $27 \mid 27$ & $23 \mid 18$ & $22 \mid 22$ & 20120 \\
\hline$\geq \$ 45000$ & $28 \mid 45$ & $15 \mid 25$ & $18 \mid 26$ & $44 \mid 52$ \\
\hline \multicolumn{5}{|l|}{ Gastrectomy } \\
\hline$<\$ 25000$ & $14 \mid 15$ & $34 \mid 39$ & 31127 & $21 \mid 17$ \\
\hline$\$ 25000-\$ 34999$ & $31 / 19$ & $37 \mid 22$ & $26 \mid 23$ & $15 \mid 15$ \\
\hline$\$ 35000-\$ 44999$ & $28 \mid 21$ & $15 \mid 18$ & 22120 & $26 \mid 17$ \\
\hline$\geq \$ 45000$ & 25144 & $11 \mid 19$ & 19129 & $36 \mid 49$ \\
\hline \multicolumn{5}{|l|}{ Lung resection } \\
\hline$<\$ 25000$ & $14 \mid 14$ & $34 \mid 41$ & $29 \mid 21$ & $15 \mid 12$ \\
\hline \multicolumn{5}{|l|}{ Prostatectomy } \\
\hline$<\$ 25000$ & $12 \mid 9$ & 28129 & $23 \mid 14$ & $14 \mid 6$ \\
\hline$\$ 25000-\$ 34999$ & $26 \mid 18$ & $25 \mid 21$ & $26 \mid 19$ & $22 \mid 14$ \\
\hline$\$ 35000-\$ 44999$ & 27122 & $21 \mid 21$ & 25123 & 25120 \\
\hline$\geq \$ 45000$ & $32 / 49$ & $22 \mid 27$ & 21129 & $34 \mid 54$ \\
\hline
\end{tabular}

Further efforts are needed to reduce disparities in access to high-volume hospitals across the nation. Such practice has been described as selective referral, which, according to previous studies, may result in more optimal postsurgical complications and mortality. ${ }^{9} 33$ While this remains a mere hypothesis, not practically proven to be effective, its theoretical application has been tested and recommended for some surgeries. ${ }^{33}$ However, if public health policymakers were to adopt the implementation of selective referral, they may be confronted with several challenges. For one, disparities due to socioeconomic or racial factors have long been recognised as a public health issue, not limited to healthcare access. Inequities from work, wealth, income and education levels, housing and overall standard of living represent well-founded causes of disparities not only for access to high-volume institutions, but also to early detection and treatment. In addition, discrimination also occurs, independent of insurance status and income levels. ${ }^{29}$ In consequence, difficulties may arise in the attempt to reduce disparities to utilisation of high-volume hospitals, if disparities occur at another level. Specifically, it may be that high-volume patients have previously undergone better preventive healthcare-a timely treatment management and other secondary care services relative to low-volume patients, which gives them an advantage at the time of surgery. 

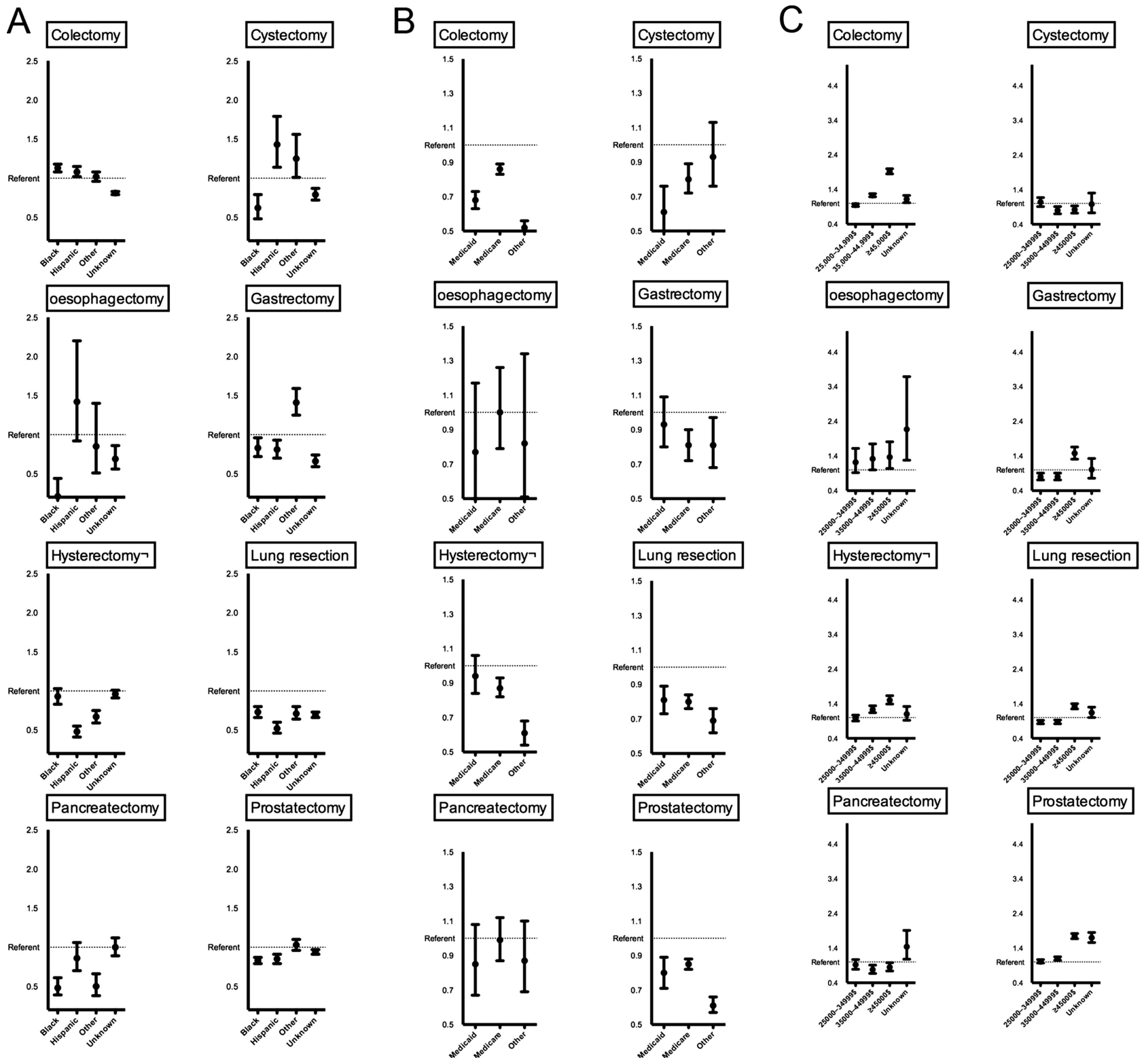

Figure 1 Procedure-specific multivariable generalised linear regression models predicting the rate of high-volume hospital utilisation focusing on the effect of race (A), insurance status (B) and ZIP code income (C) modulated as OR. Referent category for all comparisons was Caucasian race, private insurance and income $<\$ 25000$, respectively. Error bars represent $95 \%$ Cls.

On the other hand, the process of regionalisation itself may further exacerbate or maintain existing disparities. ${ }^{19}$ This may be due to patient-related health behaviour, such as the mere lack of knowledge that higher procedurespecific volume can improve outcomes, or to unavailable means of transportation. ${ }^{9}$ Under these circumstances, the conceptualisation and operationalisation of programmes seeking to reduce disparities in utilisation of high-volume complex surgical oncological procedures may not be evident. However, failing to promptly address cancer disparities, whether it is access to quality care, preventive measures or early treatment and intervention, may ultimately result in an irreconcilable divergence of the healthcare system among select segments of the US population.

Our study is not devoid of limitations. Primarily, owing to the retrospective nature of the database, as well as the limited information captured, it was not possible to know why patients were not able to access high-volume hospitals. For example, some physicians due to restrictions on insurance types are unable to accept Medicare and Medicaid patients, which would ultimately represent a different type of barrier, not necessarily related to patient-directed discrimination, but merely for economical reasons. Other confounders that may restrict access to care may also have been operational. In addition, the NIS lacks clinical information, which prevented us from adjusting for disease aggressiveness. Moreover, patientlevel income information was not available. Instead, we relied on a county-derived estimation of patients' income, which may be considered less reliable. Importantly, the current findings may be strictly applicable to the healthcare system in the USA, which may not 
be indicative of other regions/countries with differing health-economic systems. Finally, the database used, although large and generalisable, inherits conventional limitations inherent of administrative cohorts, such as errors in data collection, procedure classification and coding. ${ }^{34}$

\section{CONCLUSIONS}

Our study confirms the existence of racial, payer and socioeconomic disparities for high-volume hospital utilisation, across several major complex surgical oncological procedures within the USA. Such disparities may vary depending on the type of cancer. Finally, causes of cancer disparities that pertain to racial, insurance and/ or socioeconomic characteristics often reflect complex interrelated associations.

\section{Author affiliations}

${ }^{1}$ Cancer Prognostics and Health Outcomes Unit, University of Montreal Health Center, Montreal, Canada

${ }^{2}$ Vattikuti Urology Institute, Henry Ford Health System, Detroit, Michigan, USA ${ }^{3}$ Division of General Surgery, University of Montreal Health Center, Montreal, Canada

${ }^{4}$ Department of Radiation Oncology Brigham and Women's Hospital/DanaFarber Cancer Institute, Harvard Medical School, Boston, Massachusetts, USA ${ }^{5}$ Department of Medical Oncology, Dana-Farber Cancer Institute, Brigham and Women's Hospital, Harvard Medical School, Boston, Massachusetts, USA ${ }^{6}$ Department of Surgery, Division of Urology, Brigham and Women's Hospital/ Dana-Farber Cancer Institute, Harvard Medical School, Boston,

Massachusetts, USA

Contributors All authors contributed significantly to the following areas: (1) conception and design, or analysis and interpretation of data. (2) Drafting of the article or revising it critically for important intellectual content. (3) Final approval of the version to be published.

Funding This research received no specific grant from any funding agency in the public, commercial or not-for-profit sectors.

Competing interests None.

Provenance and peer review Not commissioned; externally peer reviewed.

Data sharing statement No additional data are available.

Open Access This is an Open Access article distributed in accordance with the Creative Commons Attribution Non Commercial (CC BY-NC 3.0) license, which permits others to distribute, remix, adapt, build upon this work noncommercially, and license their derivative works on different terms, provided the original work is properly cited and the use is non-commercial. See: http:// creativecommons.org/licenses/by-nc/3.0/

\section{REFERENCES}

1. Hillner BE, Smith TJ, Desch CE. Hospital and physician volume or specialization and outcomes in cancer treatment: importance in quality of cancer care. J Clin Oncol 2000;18:2327-40.

2. Birkmeyer JD, Siewers AE, Finlayson EVA, et al. Hospital volume and surgical mortality in the United States. N Engl J Med 2002;346:1128-37.

3. Finlayson EVA, Goodney PP, Birkmeyer JD. Hospital volume and operative mortality in cancer surgery: a national study. Arch Surg 2003:138:721-5; discussion 26.

4. Dimick JB, Wainess RM, Cowan JA, et al. National trends in the use and outcomes of hepatic resection1. J Am Coll Surg 2004;199:31-8.

5. Ellison LM, Trock BJ, Poe NR, et al. The effect of hospital volume on cancer control after radical prostatectomy. J Urol 2005;173:2094-8.

6. Begg CB, Cramer LD, Hoskins WJ, et al. Impact of hospital volume on operative mortality for major cancer surgery. JAMA 1998;280:1747-51.
7. Bach PB, Cramer LD, Schrag D, et al. The influence of hospital volume on survival after resection for lung cancer. $N$ Engl $J$ Med 2001;345:181-8.

8. The Leapfrog Group: Purchasing principles. Secondary 2012. http:// www.leapfroggroup.org/

9. Dudley RA, Johansen $\mathrm{KL}$, Brand $\mathrm{R}$, et al. Selective referral to high-volume hospitals: estimating potentially avoidable deaths. JAMA 2000;283:1159-66.

10. Trinh Q-D, Sun M, Sammon J, et al. Leapfrog volume thresholds and perioperative complications after radical prostatectomy. Cancer 2012;118:4991-8.

11. Haynes M, Smedley B. The unequal burden of cancer: an assessment of $\mathrm{NIH}$ research and programs for ethnic minorities and the medical undeserved. Washington: National Academic Press, 1999.

12. Kinsey $\mathrm{T}$, Jemal $\mathrm{A}$, Liff $\mathrm{J}$, et al. Secular trends in mortality from common cancers in the United States by educational attainment, 1993-2001. J Natl Cancer Inst 2008;100:1003-12.

13. Pappas G, Queen $\mathrm{S}$, Hadden W, et al. The increasing disparity in mortality between socioeconomic groups in the United States, 1960 and 1986. N Engl J Med 1993;329:103-9.

14. Jemal A, Ward E, Anderson R, et al. Widening of socioeconomic inequalities in US death rates, 1993-2001. PLOS ONE 2008;3: e2191.

15. Trinh Q-D, Sun M, Sammon J, et al. Disparities in access to care at high-volume institutions for uro-oncologic procedures. Cancer 2012;118:4421-6.

16. Byers T, Mouchawar J, Marks J, et al. The American Cancer Society challenge goals. How far can cancer rates decline in the U.S. by the year 2015? Cancer 1999;86:715-27

17. US Department of Health and Human Services. With understanding and improving health. Washington, 2000.

18. HCUP Nationwide Inpatient Sample (NIS). Healthcare Cost and Utilization Project (HCUP). 2007-2009. Secondary Healthcare Cost and Utilization Project (HCUP). 2007-2009. 2009. http://www. hcup-us.ahrq.gov/nisoverview.jsp

19. Liu JH, Zingmond DS, McGory ML, et al. Disparities in the utilization of high-volume hospitals for complex surgery. JAMA 2006;296:1973-80.

20. Charlson M, Pompei P, Ales K, et al. A new method of classifying prognostic comorbidity in longitudinal studies: development and validation. J Chronic Dis 1987;40:373-83.

21. Deyo R, Cherkin D, Ciol M. Adapting a clinical comorbidity index for use with ICD-9-CM administrative databases. J Clin epidemiol 1992;45:613-19.

22. Chukmaitov AS, Menachemi N, Brown SL, et al. Is there a relationship between physician and facility volumes of ambulatory procedures and patient outcomes? J Ambul Care Manage 2008;31:354-69.

23. Dimick JB, Cowan JA, Colletti LM, et al. Hospital teaching status and outcomes of complex surgical procedures in the United States. Arch Surg 2004;139:137-41.

24. Kernisan LP, Lee SJ, Boscardin WJ, et al. Association between hospital-reported Leapfrog Safe Practices Scores and inpatien mortality. JAMA 2009;301:1341-8.

25. Khuri SF, Henderson WG. The case against volume as a measure of quality of surgical care. World J Surg 2005;29:1222-9.

26. Konety BR, Allareddy V, Modak S, et al. Mortality after major surgery for urologic cancers in specialized urology hospitals: are they any better? J Clin Oncol 2006:24:2006-12.

27. Konety BR, Dhawan V, Allareddy V, et al. Impact of hospital and surgeon volume on in-hospital mortality from radical cystectomy: data from the health care utilization project. J Urol 2005;173:1695-700.

28. Siegel R, Naishadham D, Jemal A. Cancer statistics, 2012. CA Cancer J 2012:62:10-29.

29. Gross $\mathrm{C}$, Smith $\mathrm{B}$, Wolf $\mathrm{E}$, et al. Racial disparities in cancer therapy: the gap narrow between 1992 and 2002? Cancer 2008;112:900-08.

30. Keeler EB, Rubenstein LV, Kahn KL, et al. Hospital characteristics and quality of care. JAMA 1992;268:1709-14.

31. Broder S. Progress and Challenges in the National Cancer Program. In: Brugge J, Curran T, Harlow E, McCormick F, eds. Origins of Human Cancer: A comprehensive Review. Plainview, NY: cold spring Harbor Laboratory Press, 1991:27-33.

32. American Cancer Society. Cancer facts \& figures 2011. Atlanta: American Cancer Society, 2011.

33. Hollenbeck BK, Dunn RL, Miller DC, et al. Volume-based referral for cancer surgery: informing the debate. J Clin Oncol 2006;25:91-6.

34. Jollis J, Ancukiewicz M, DeLong E, et al. Discordance of databases designed for claims payment versus clinical information systems. Implications for outcomes research. Ann Intern Med 1993;119:844-50 